\title{
Effectiveness of combined magnetic field bone growth stimulation on lumbar spinal fusion outcomes: a single center retrospective analysis comparing combined magnetic field to no-stimulation
}

\author{
Ramin Raiszadeh¹, Kamshad Raiszadeh ${ }^{1}$, Laura Eaton ${ }^{2 *}$, Paul Kim¹, Choll Kim¹
}

\author{
${ }^{1}$ Department of Spine Surgeons of San Diego, San Diego, CA, USA \\ ${ }^{2}$ Department of Clinical Research and Medical Affairs, UltaMed Corporation, Fort Lauderdale, FL, USA
}

\author{
Received: 19 February 2020 \\ Revised: 03 March 2020 \\ Accepted: 05 March 2020

\section{*Correspondence: \\ Ms. Laura Eaton, \\ E-mail: laura@ultamed.com}

Copyright: ( ) the author(s), publisher and licensee Medip Academy. This is an open-access article distributed under the terms of the Creative Commons Attribution Non-Commercial License, which permits unrestricted non-commercial use, distribution, and reproduction in any medium, provided the original work is properly cited.

\begin{abstract}
Background: The objective of this retrospective study was to assess the effect of combined magnetic field (CMF) bone growth stimulation on lumbar fusion outcomes, as compared to no-stimulation.

Methods: This study reviewed fusion efficacy of a consecutive cohort of 652 patients who underwent lumbar fusion surgery at our institution between 2001 and 2018. Fusion status was determined via radiographic analysis, with four surgeons contributing data to this study. The minimum patient follow-up time was 6 months. Previously identified risk factors (i.e. smoking status) were also collected. Statistical analysis was performed using cross-tabulation tests with chi-square analyses, one-way ANOVA's, and Tukey's range tests. 53\% (343/652) of patients had undergone adjuvant treatment with CMF stimulation.

Results: Patients treated with CMF stimulation had significantly greater fusion success of $97 \%$ compared to no stimulation at $62 \%(\mathrm{p}<0.00001)$. Further, it was observed that smokers had a significantly higher fusion rate with CMF treatment than without electrical stimulation (94\% vs $61 \%, \mathrm{p}=0.000032)$.

Conclusions: Additional studies to evaluate the effectiveness of CMF treatment in patients with risk factors are warranted.
\end{abstract}

Keywords: Lumbar, Spine, Spinal fusion, Combined magnetic field, Electrical bone growth stimulation

\section{INTRODUCTION}

Lumbar spinal fusion procedures are commonly used to alleviate pain and suffering due to spinal stenosis, degenerative disc diseases, spondylolisthesis, scoliosis, and trauma. According to an analysis of national inpatient sample (NIS), 2004 to 2015 published by Martin et al (2019) the U.S. the volume of elective lumbar fusion surgeries increased $62.3 \%$ (or $32.1 \%$ per 100,000 U.S. adults) from 122,679 cases $(60.4$ per 100,000) in 2004 to $199,140(79.8$ per 100,000$)$ in 2015 . While the prevalence of spinal pathologies is not known, the rate of elective lumbar fusion surgery in the U.S. increased most for spondylolisthesis and scoliosis. Increases in spinal fusion surgery was greatest among age 65 or older. Additionally, aggregate hospital costs increased $177 \%$ during a 12 -year period spanning from 2004 to 2014, exceeding more than $\$ 50,000$ per admission. ${ }^{1}$

Spinal fusion surgery is designed to stop the motion at a painful vertebral segment, which in turn should decrease pain generated from the joint. There are many approaches 
to lumbar spinal fusion surgery, and all involve adding a bone graft to a segment of the spine to cause two vertebral bodies to grow together into one long bone, and setting up a biological response that causes the bone graft to grow between the two vertebral elements to create a bone fusion. The boney fusion results in one fixed bone replacing a mobile joint which stops motion at that joint segment.

Failure of the vertebrae to fuse, or pseudarthrosis, is the most significant cause of clinical failure following spinal fusion. ${ }^{2}$ The consequences of pseudoarthrosis include poor clinical outcomes and require extensive medical expenditure. $^{3}$ Chun et al found that the pseudarthrosis rate following lumbar fusion ranged from $5 \%$ to $35 \%$. $^{4}$ Prognostic factors that have found to be significantly related to predicting surgical outcome in spinal fusion patients include smoking status, diagnosis, use of hardware, insurance status, preoperative SGPT (alanine transaminase) level, prior operations or decompressions, diabetes, obesity and age. ${ }^{5,6}$ In a comprehensive literature review, Berman et al found several studies that demonstrated smoking increases the risk of pseudoarthrosis following lumbar fusion. Since the consequences of pseudoarthrosis include poor clinical outcomes and extensive medical expenditure, it is crucial to optimize care for all lumbar fusion patients. ${ }^{7,8}$

Given the number of patients undergoing lumbar spinal fusion procedures and the risk for failed fusion, adjunctive therapies to enhance the probability of fusion in high risk populations have been employed, such as bone growth stimulators. ${ }^{9}$ The clinical benefits of electrical stimulation as an adjunct to spinal fusion has been increasingly recognized over the past 30 years with scientific studies better defining their mechanisms of action and supporting treatment validity. These devices are prescribed postoperatively to help mimic the body's natural healing environment by generating electrical fields that activate the body's internal repair mechanisms which promote bone growth. ${ }^{10}$

Electrical and electromagnetic fields (EMF) are known to encourage bone healing in a similar fashion to mechanical stress and load bearing applications. ${ }^{11,12}$ Physicians can prescribe adjuvant treatment with bone growth stimulators (BGS) devices that generate EMFs to improve the likelihood of vertebrae fusion success. Although the exact mechanism of action is not completely understood, EMF stimulation has been shown to upregulate bone-promoting growth factors, including IGF-II, calcitonin, IL-2, calmodulin and insulin. ${ }^{7,13,14}$

There are currently three types of EMF technologies utilized for lumbar fusion, including direct current (DC), capacitive coupling (CC), and inductive coupling. Inductive coupling technology can include pulsed electromagnetic field stimulation (PEMF) and combined magnetic field stimulation (CMF). Spinal fusion rates have been reported to improve from $18-32 \%$ compared to no BGS stimulation in randomized trials. ${ }^{9}$ Moreover, a recent meta-analysis by Cottrill et al found that electrical stimulation technologies can significantly improve the likelihood of vertebrae fusion (OR 2.26, $\mathrm{p}<0.001$ ), including inductive coupling technologies (OR 2.45, $\mathrm{p}=0.014) .{ }^{15}$

The EMF generated by CMF can stimulate insulin growth factor II expression and osteoblast proliferation to promote bone healing. ${ }^{16,17}$ A prospective, multi-center, randomized double-blinded study found that adjuvant treatment with CMF significantly improved the lumbar fusion rate from $43 \%$ for placebo patients to $64 \%$ for patients with an active device $(\mathrm{p}=0.003)$ at 9 months follow-up. ${ }^{17}$ Similarly, a prospective, multi-center, randomized double-blinded study found the PEMF stimulation significantly improved lumbar fusion from $65 \%$ in control patients to $83 \%$ ( $p>0.005$ ) at 12 months. ${ }^{18}$ Findings from Linovitz et al and Mooney et al included approximately 200 evaluable patients each (201 and 195, respectively). ${ }^{18,19}$

Despite demonstrating a clinical benefit for lumbar fusion, the prescription rate for BGS devices for lumbar fusion remains at less than $20 \%$ therefore, as a quality improvement project at our institution we sought to better understand outcomes of BGS device treated patients after lumbar spinal fusion surgery. ${ }^{20}$ In a retrospective chart analysis, we compared patients treated with $\mathrm{CMF}$ stimulation to those patients who received no stimulation after lumbar spinal fusion surgery. Additional analysis was performed to specifically measure the effect on smokers, older patients ( $>55$ years) and patients with bone disorders.

\section{METHODS}

This study was a retrospective review of lumbar spinal fusion surgeries performed between 2001 and 2018 by four surgeons at the spine institute of San Diego (SISD), CA, USA. The data was prospectively collected in SISD's centricity patient management solution electronic medical record system through chart abstraction.

Patients were included if they had undergone lumbar spinal fusion surgery at our institution and received $\mathrm{CMF}$ bone growth stimulation post-operatively or received no stimulation. Four spine surgeons contributed data to this analysis. Only subjects with documented radiographic evidence of fusion or non-fusion were included. Subjects were excluded if they were still under evaluation at the time of analysis ( $<6$ months follow-up), had undergone bone growth stimulation with another type of EMF technology, or were lacking radiographic analysis data within the available medical records. A total of 1,377 charts were analyzed with 652 patients satisfying our eligibility criteria. Of the 652 eligible subjects, 343 were treated with CMF bone growth stimulation postoperatively and 309 received no stimulation. The study was conducted with ethical approval from Veritas IRB.

The CMF device (Spinalogic, DJO Global, TX) utilized in this study is a non-invasive, inductive coupling BGS 
device that produces very low combined static and dynamic electromagnetic fields on the order of the earth's magnetic field. The CMF device is lightweight, portable, and battery powered. It is shaped to accommodate curvature of the spine and designed to promote fusion. The device can be applied over a cast, brace or clothing. Patients who received CMF stimulation were instructed to wear the device post-operatively for 30 minutes per day. Software specifications programmed into the device prohibit patients from receiving more than one treatment in 24 hours. Additionally, the device shuts off and cannot be used after 270 days of use.

A radiologist blinded to treatment utilized flexionextension to assess fusion status in all included patients. Fusion was defined as solid bridging of bone through fusion hardware, full consolidation of interbody space, no evidence of screw loosening, and no interbody motion. The classification of not fused was assigned if there was no radiographic evidence of bony consolidation and the time since surgery was greater than 12 months.

Statistical analysis was performed using ANOVA, chisquared test and Tukey's HSD range test to evaluate whether observed outcome differences between spinal fusion patients who received CMF stimulation and those with no stimulation were statistically significant. The data was collected and analyzed by Qualitee 360, a third-party healthcare data analytics consulting company.

\section{RESULTS}

The CMF stimulator was used in 53\% (343/652) of patients, while 47\% (309/652) received no stimulation. The overall baseline patient demographics and characteristics for patients in the CMF stimulation and no stimulation groups $(n=652)$ are presented in (Table 1$)$. The risk profile for the overall patient population of 652 patients consisted of $59 \% \geq 55$ years, $16 \%$ who were current smokers, $13 \%$ with bone disorders such as osteopenia or osteoporosis, $47 \%$ with previous history of spine surgery and $17 \%$ being revision surgeries (Table 1). The mean age at time of surgery was 57.84 (SD 13.41) years and the mean body mass index was 28.96 (SD 5.6) pounds per meter squared. Fifty-two percent (52\%) were males and $48 \%$ were females. Pre-operative primary diagnoses included spinal stenosis (26\%), spondylolisthesis (26\%), degenerative disc disease (12\%), spinal instability $(5 \%)$, disc herniation $(5 \%)$, pseudoarthrosis $(4 \%)$, prior fusion surgery $(3 \%)$, prior discectomy $(1 \%)$, adjacent segment disease $(0.8 \%)$, other (16\%) (Table 2).

Table 1: Baseline patient and outcome demographics for CMF stimulation and no stimulation groups $(\mathrm{n}=652)$.

\begin{tabular}{|c|c|c|c|c|c|}
\hline Category & Variable & $\begin{array}{l}\text { CMF stimulation } \\
\text { group } \\
(\mathbf{n = 3 4 3 )}\end{array}$ & $\begin{array}{l}\text { No stimulation } \\
\text { group } \\
(\mathrm{n}=309)\end{array}$ & $\begin{array}{l}\text { Total } \\
\text { N/n }(\%)\end{array}$ & P value \\
\hline \multirow{2}{*}{ Gender } & Female & 162 & 151 & $313 / 652(48)$ & \multirow{2}{*}{0.68} \\
\hline & Male & 181 & 158 & $339 / 652$ (52) & \\
\hline \multirow[b]{2}{*}{ Smoking history } & Current smoker & 66 & 36 & $102 / 652(16)$ & \multirow[b]{2}{*}{0.0077} \\
\hline & $\begin{array}{l}\text { Non-smoker/former } \\
\text { smoker }\end{array}$ & 277 & 273 & $350 / 652(54)$ & \\
\hline \multirow{2}{*}{ Age bracket } & $\leq 55$ years & 140 & 130 & $270 / 652(41)$ & \\
\hline & $>55$ years & 203 & 179 & $382 / 652(59)$ & \\
\hline \multirow{4}{*}{ Bone disorder } & Osteopenia & 18 & 10 & $28 / 652(4)$ & \multirow{2}{*}{0.21} \\
\hline & No osteopenia & 325 & 299 & $624 / 652(96)$ & \\
\hline & Osteoporosis & 27 & 28 & $55 / 652(8)$ & \multirow{2}{*}{0.59} \\
\hline & No osteoporosis & 316 & 281 & $597 / 652(92)$ & \\
\hline \multirow{2}{*}{$\begin{array}{l}\text { Previous spine } \\
\text { surgery }\end{array}$} & No & 173 & 133 & $306 / 652(47)$ & \multirow{2}{*}{0.51} \\
\hline & Yes & 170 & 176 & $346 / 652(53)$ & \\
\hline \multirow{2}{*}{ Revision surgery } & No revision & 294 & 244 & $538 / 652(83)$ & \multirow{2}{*}{0.02} \\
\hline & Revision surgery & 49 & 65 & $114 / 652(17)$ & \\
\hline \multicolumn{6}{|c|}{ Outcome demographics } \\
\hline \multirow{2}{*}{$\begin{array}{l}\text { Surgical } \\
\text { complications }\end{array}$} & $\begin{array}{l}\text { No surgical } \\
\text { complications }\end{array}$ & 337 & 306 & 643/652 (99) & \multirow{2}{*}{0.39} \\
\hline & $\begin{array}{l}\text { Surgical } \\
\text { complications }\end{array}$ & 6 & 3 & $9 / 652(1)$ & \\
\hline \multirow{2}{*}{$\begin{array}{l}\text { Post-operative } \\
\text { complications }\end{array}$} & $\begin{array}{l}\text { Post-operative } \\
\text { complications }\end{array}$ & 29 & 22 & $51 / 652(8)$ & \multirow{2}{*}{09.53} \\
\hline & $\begin{array}{l}\text { No post-operative } \\
\text { complications }\end{array}$ & 314 & 287 & $601 / 652(92)$ & \\
\hline
\end{tabular}


Table 2: Primary diagnosis and surgical technique demographics $(n=652)$.

\begin{tabular}{|c|c|c|c|c|c|}
\hline Category & $\begin{array}{l}\text { CMF stimulation } \\
\text { group }(n=343)\end{array}$ & $\begin{array}{l}\text { No stimulation } \\
\text { group }(\mathrm{n}=309)\end{array}$ & $\begin{array}{l}\text { Total } \\
\text { N/n }(\%)\end{array}$ & $P$ value & $\begin{array}{l}\text { Overall } \\
\text { p value }\end{array}$ \\
\hline \multicolumn{6}{|l|}{ Primary diagnosis } \\
\hline Adjacent segment disease & 2 & 3 & $5 / 652(0.8)$ & 0.57 & \multirow{11}{*}{0.54} \\
\hline Degenerative disc disease & 34 & 44 & $78 / 652(12)$ & 0.09 & \\
\hline Disc herniation & 15 & 18 & $33 / 652(5)$ & 0.4 & \\
\hline Instability & 24 & 9 & $33 / 652(5)$ & 0.02 & \\
\hline Prior discectomy & 4 & 3 & $7 / 652(1)$ & 0.81 & \\
\hline Prior fusion surgery & 15 & 7 & $22 / 652(3)$ & 0.14 & \\
\hline Pseudoarthrosis & 10 & 14 & $24 / 652(4)$ & 0.27 & \\
\hline Spondylolisthesis & 80 & 91 & $171 / 652(26)$ & 0.08 & \\
\hline Stenosis & 89 & 83 & $172 / 652(26)$ & 0.79 & \\
\hline $\begin{array}{l}\text { Symptomatic mechanical } \\
\text { disc collapse }\end{array}$ & 0 & 1 & $1 / 652(0.2)$ & 0.94 & \\
\hline Other & 70 & 36 & 106/652(16) & 0.002 & \\
\hline \multicolumn{6}{|l|}{ Surgical approach } \\
\hline Anterior & 150 & 80 & $230 / 652(35)$ & $<0.00001$ & \multirow{5}{*}{0.00001} \\
\hline Lateral & 20 & 17 & $37 / 652(6)$ & 0.86 & \\
\hline Posterior & 109 & 175 & 284/652 (44) & $<0.00001$ & \\
\hline Anterior and posterior & 55 & 33 & $88 / 652(13)$ & 0.045 & \\
\hline Other & 9 & 4 & $13 / 652(2)$ & 0.23 & \\
\hline \multicolumn{6}{|l|}{ Operative approach } \\
\hline Open & 32 & 17 & & 0.08 & \multirow{3}{*}{0.16} \\
\hline Minimally invasive & 309 & 289 & $598 / 652(92)$ & 0.71 & \\
\hline Other & 2 & 3 & & 0.58 & \\
\hline \multicolumn{6}{|l|}{ Instrumentation } \\
\hline Pedicle screws & 202 & 187 & $389 / 652(60)$ & 0.67 & \multirow{3}{*}{0.18} \\
\hline Percutaneous screws & 57 & 63 & $120 / 652(18)$ & 0.17 & \\
\hline Other & 84 & 59 & $143 / 652(22)$ & 0.1 & \\
\hline \multicolumn{6}{|l|}{ Hardware } \\
\hline Plates & 44 & 53 & $97 / 652(15)$ & 0.12 & \multirow{3}{*}{0.23} \\
\hline Screws and nuts & 261 & 218 & 479/652 (73) & 0.11 & \\
\hline Other & 38 & 38 & $76 / 652(12)$ & 0.63 & \\
\hline \multicolumn{6}{|l|}{ Tissue implanted } \\
\hline Allograft & 164 & 149 & $313 / 652(48)$ & 0.92 & \multirow{4}{*}{0.73} \\
\hline Autograft & 6 & 6 & $12 / 652(2)$ & 0.86 & \\
\hline Allograft and autograft & 172 & 151 & $323 / 652(50)$ & 0.71 & \\
\hline Other & 1 & 3 & $4 / 652(<1)$ & 0.27 & \\
\hline
\end{tabular}

Table 3: Fusion rates by treatment group for CMF stimulation as compared to no stimulation $(n=652)$.

\begin{tabular}{|c|c|c|c|}
\hline & $\begin{array}{l}\text { CMF } \\
\text { stimulation } \\
\text { group }(n=343) \\
\mathbf{N}(\%)\end{array}$ & $\begin{array}{l}\text { No } \\
\text { stimulation } \\
\text { group } \\
(\mathbf{n}=309) \mathbf{N} \\
(\%)\end{array}$ & P value \\
\hline Fused & $331 / 343(97)$ & $192 / 309(62)$ & \multirow[b]{2}{*}{$<0.00001$} \\
\hline $\begin{array}{l}\text { Not } \\
\text { fused }\end{array}$ & $12 / 343(3)$ & $117 / 309(38)$ & \\
\hline
\end{tabular}

The majority (44\%) of cases were done using a posterior surgical approach, with $35 \%$ being anterior, $13 \%$ being anterior and posterior, $6 \%$ being lateral, and $2 \%$ being other. In most cases the tissue implant was allograft (48\%), or autograft and allograft $(50 \%)$ with $2 \%$ of cases being only autograft and $<1 \%$ being other. Ninety-two percent $(92 \%)$ of cases were minimally invasive. The majority of fusion procedures were cage fusion using polyetheretherketone cages. Seventy-three percent $(73 \%)$ of patients had screws and nuts, $15 \%$ had plates, and $12 \%$ had other hardware placed during surgery. Sixty percent $(60 \%)$ of patients had pedicle screws, while $18 \%$ had percutaneous screws and $22 \%$ had other instrumentation 
(Table 2). Patient demographics by treatment group (CMF vs. no stimulation) are provided in Table 1.

CMF stimulation was observed to have a significantly higher rate of fusion success $(97 \%)$ as compared to no stimulation (62\%), $\mathrm{p}<0.00001$ (Table 3).

The effect of CMF stimulation on high-risk patients was examined, including smoking status, osteopenia, osteoporosis, age over 55, and history of revision surgery or previous spine surgery (Table 4).
Smoking is a high risk factor for lumbar spinal surgery and has been shown to be associated with an increased risk of pseudoarthrosis and poor recovery. A history of smoking is an established indication for the employing the use of BGSs after spinal fusion surgery. Our results show that CMF stimulation was significantly associated with improved the fusion rate for smokers from $61 \%$ without stimulation to a $94 \%$ fusion success rate with $\mathrm{CMF}$ stimulation $(\mathrm{p}=0.000032)$.

Table 4: Fusion rates by patient factors for CMF stimulation group as compared to no stimulation group (n=652).

\begin{tabular}{|c|c|c|c|c|c|c|}
\hline \multirow{3}{*}{ Patient factor } & \multirow{3}{*}{ Variable } & \multicolumn{4}{|l|}{ Group } & \multirow{3}{*}{ P value } \\
\hline & & \multicolumn{2}{|c|}{ CMF stimulation $(n=343)$} & \multicolumn{2}{|c|}{ No stimulation $(n=309)$} & \\
\hline & & $\begin{array}{l}\text { Fused } \\
\mathbf{N}(\%)\end{array}$ & $\begin{array}{l}\text { Not fused } \\
\mathbf{N}(\%)\end{array}$ & $\begin{array}{l}\text { Fused } \\
\mathbf{N}(\%)\end{array}$ & $\begin{array}{l}\text { Not fused } \\
\text { N }(\%)\end{array}$ & \\
\hline \multirow{2}{*}{ Gender } & Female & $158(98)$ & $4(2)$ & $92(61)$ & $59(39)$ & $<0.00001$ \\
\hline & Male & $173(96)$ & $8(4)$ & $100(63)$ & $58(37)$ & $<0.00001$ \\
\hline \multirow{2}{*}{$\begin{array}{l}\text { Smoking } \\
\text { history }\end{array}$} & $\begin{array}{l}\text { Current } \\
\text { smoker }\end{array}$ & $62(94)$ & $4(6)$ & $22(61)$ & $14(39)$ & 0.000032 \\
\hline & $\begin{array}{l}\text { Non/former } \\
\text { smoker }\end{array}$ & $269(97)$ & $8(3)$ & $170(62)$ & $103(38)$ & $<0.00001$ \\
\hline \multirow[t]{2}{*}{ Bone disorder } & Osteopenia & $17(94)$ & $1(6)$ & $4(40)$ & $6(60)$ & 0.0014 \\
\hline & Osteoporosis & $27(100)$ & $0(0)$ & $13(46)$ & $15(64)$ & 0.000035 \\
\hline \multirow{2}{*}{ Age in years } & $\leq 55$ & $134(96)$ & $6(4)$ & $89(68)$ & $41(32)$ & $<0.00001$ \\
\hline & $55+$ & $197(97)$ & $6(3)$ & $103(58)$ & $76(42)$ & $<0.00001$ \\
\hline \multicolumn{2}{|c|}{ Revision surgery } & $48(98)$ & $1(2)$ & $41(63)$ & $24(37)$ & $<0.00001$ \\
\hline \multicolumn{2}{|c|}{ Previous spine surgery } & $161(95)$ & $9(5)$ & $85(64)$ & $48(36)$ & $<0.00001$ \\
\hline \multicolumn{2}{|c|}{ Use of pre-operative pain meds } & $245(96)$ & $11(4)$ & $139(63)$ & $82(37)$ & $<0.00001$ \\
\hline
\end{tabular}

Previous studies have suggested that male patients do not benefit from CMF stimulation to the same magnitude as women however, our study observed that there was little difference in fusion rate between genders for both the CMF stimulation group (98\% of females fused and $96 \%$ of males) and no-stimulation group (61\% of females fused and $63 \%$ of males).

In our study, patients over the age of 55 had significant fusion success rates over no stimulation: $97 \%$ fusion success with CMF stimulation versus $58 \%$ with no stimulation $(\mathrm{p}<0.00001)$. A history of previous spine surgery and revision surgery patients also responded well to CMF stimulation. The fusion success rate in patients with a history of previous spine surgery who underwent CMF stimulation was $95 \%$ as compared to $64 \%$ in nonstimulation patients $(\mathrm{p}<0.00001)$. Patients undergoing CMF stimulation after revision surgery had a $98 \%$ fusion success rate as compared to $63 \%$ in the no stimulation group $(\mathrm{p}<0.00001)($ Table 4$)$.

Overall, most patients (68\%) were in the 6 to 9 months range for time to fusion, while $29 \%$ were $9-12$ months and only $2 \%$ were $12+$ months. The mean time to fusion for the CMF stimulation and no stimulations groups were 256 days and 244 days, respectively. There was no statistically significant difference in mean time to fusion between groups.

Lack of radiographic evidence of bony consolation after 12 months was classified as no fusion. In the no stimulation group 38\% (117/309) failed to fuse, while only $3 \%$ of the patients receiving CMF stimulation failed to fuse $(\mathrm{p}<0.00001)$. Of the patients who did not fuse, $91 \%$ $(117 / 129)$ received no electrical stimulation. The majority $(64 \%)$ were over the age of 55 and $14 \%$ were current smokers. The mean age of patients who did not fuse was $58.68(\mathrm{SD} 15.05)$ years.

\section{Safety}

Surgical complications occurred at a rate of $1 \%(9 / 652)$. Post-operative adverse events occurred at a rate of $8 \%$ (51/652) (Table 1). Exposure to the CMF device was not associated with an increased risk of post-operative adverse events.

\section{DISCUSSION}

Achieving a solid fusion is the goal of spinal fusion procedures. Prevention of complications, such as pseudoarthrosis (unsuccessful spinal fusion), leads to improved clinical and functional outcomes. ${ }^{1}$ Therefore, the 
best treatment for pseudoarthrosis is to prevent it from occurring after the initial operation. ${ }^{4}$

Patients who underwent CMF stimulation had a statistically significant fusion rate $(\mathrm{p}<0.00001)$ over no stimulation, which is corroborated in the scientific literature. Park et al conducted a systematic review which examined the effect of electrical stimulation on lumbar fusion outcomes following PEMF stimulation to be in the range of $64 \%$ to $83 \%$ while fusion rates with no stimulation ranged from $43 \%$ to $81 \%$. Similarly, the fusion rate following CC stimulation was $91 \%$, which was greater than the fusion rate of $82 \%$ following no stimulation. ${ }^{25}$ Linovitz et al completed a prospective randomized controlled trial to examine the effect of CMF stimulation on fusion rate. They reported a statistically significant $21 \%$ increase in fusion rates when using CMF stimulation compared to placebo at 9 months. ${ }^{19}$ In our study, among patients receiving electrical stimulation, those receiving CMF stimulation had the highest fusion rates.

The use of CMF stimulation has been shown to have benefits in certain populations, such as the elderly, postmenopausal females, and smokers, demonstrating a greater fusion response to CMF treatment. ${ }^{22}$ The use of BGSs, in general, has also been shown to be a cost effective adjunctive treatment option, and a review of the literature indicates that treatment with CMF is clinically beneficial for lumbar spinal fusions, reducing the occurrence of pseudoarthrosis, and may be economically advantageous because of less time away from work and reduced risk of reoperation. ${ }^{1,10}$ A history of previous spine surgery as well as advancing age are known risk factors for lumbar fusion surgery. ${ }^{23,24}$

Limitations of our study included a short minimum followup time (6 months), the retrospective nature of the data collection limiting our knowledge of patient compliance with device usage or wear, limited or missing data, patients lost to follow-up, groups with small pools, and the heterogeneity of the patient and physician populations.

\section{CONCLUSION}

We conducted this retrospective chart review of prospectively collected data in order to better understand the effectiveness of CMF stimulation in promoting lumbar spinal fusion under different clinical scenarios. The examination of 652 patents found that CMF simulation was superior to no-stimulation in terms of fusion success rate, smokers, age over 55, those with osteopenia or osteoporosis, as well as in patients with revision surgery or history of previous spine surgery. Use of BGS was safe and did not result in any adverse events related to product use.

We concluded that the integration of CMF BGS into the aftercare program of spinal fusion patients, specifically those at high risk for pseudoarthrosis, can potentially provide better clinical and function outcomes and a higher expected fusion rate. CMF stimulation was found to be the most effective BGS technology of those studied and is the preferred BGS in our practice.

\section{ACKNOWLEDGEMENTS}

Data abstraction was completed by Qualitee 360, a healthcare data analytics firm.

Funding: This study was funded by a grant from DJO Global

Conflict of interest: None declared

Ethical approval: The study was approved by the institutional ethics committee

\section{REFERENCES}

1. Martin BI, Mirza SK, Spina N, Spiker WR, Lawrence B, Brodke DS. Trends in Lumbar Fusion Procedure Rates and Associated Hospital Costs for Degenerative Spinal Diseases in the United States, 2004 to 2015. Spine. 2019;44(5):369-76.

2. Gruskay JA, Webb ML, Garauer JN. Methods of evaluating lumbar and cervical fusion. Spine J. 2014;14(3):531-9.

3. Miyazaki M, Tsumura H, Wang JC, Alanay A. An update on bone substitutes for spinal fusion. Europ Spine J. 2009; 18(6):783-99.

4. Chun DS, Baker KC, Hsu WK. Lumbar pseudarthrosis: a review of current diagnosis and treatment. Neuroserg FOCUS. 2015;39(4):10.

5. Jenkins LT, Jones AL, Harms JJ. Prognostic factors in lumbar spinal fusion. Contemp Orthop. 1994;29(3):173-80.

6. Gan JC, Glazer PA. Electrical stimulation therapies for spinal fusions: current concepts. Europ spine J. 2006;15(9):1301-11.

7. Berman D, Oren JH, Bendo J, Spivak J. The Effect of Smoking on Spinal Fusion. Int J Spine Surg. 2017;11:29.

8. Miyazaki M, Tsumura H, Wang J, Alanay A. An update on bone substitutes for spinal fusion. Europ Spine J. 2009;18(6):783-99.

9. Stippick TW, Sheller MR. Combined magnetic fields provide robust coverage for interbody and posterolateral lumbar spinal fusion sites. Med Biolog Engin Comput. 2016;54(1):113-22.

10. Khalifeh JM, Zohny Z, Ewan M. Electrical Stimulation and Bone Healing: A Review of Current Technology and Clinical Applications. IEEE Rev Biomed Eng. 2018;11:217-32.

11. Victoria G, Petrisor BA, Drew B, Dick D. Bone stimulation for fracture healing: What's all the fuss. Indian J Orthop. 2009;43(2):117-20.

12. Hannouche D, Petite H, Sedel L. Current trends in the enhancement of fracturre healing. J Bone Joint Surg Br. 2001;83(2):157-64.

13. Ciombor D, Aaron RK. The role of electrical stimulation in bone repair. Foot Ankle Clin. 2005;10(4):579-93. 
14. Zayzafoon M. Calcium/calmodulin signaling controls osteoblast growth and differentiation. J Cell Biochem. 2006;97(1):56-70.

15. Cottrill E, Pennington Z, Ahmed AK. The effect of electrical stimulation therapies on spinal fusion: a cross-disciplinary systematic review and metaanalysis of the preclinical and clinical data. J Neurospine Surg. 2019;8:1-21.

16. Fitzsimmons RJ, Fyaby JT, Mohan S, Magee FP, Baylink DJ. Combined magnetic fields increase insulin-like growth factor-II in TE-8 human osteosarcoma bone cell cultures. Endocrinology. 1995;136(7):3100-6.

17. Ryaby JT, Fitzsimmons RJ, Khin NA. The role of insulin-like growth factor II in magnetic field regulation of bone formation. Bioelectrochem Bioenerg. 1994;35(1-2):87-91.

18. Mooney V. A randomized double-blind prospective study of the efficacy of pulsed electromagnetic fields for interbody lumbar fusions. Spine. 1990;15(7):70812.

19. Linovitz RJ, Pathria M, Bernhardt M. Combined magnetic fields accelerate and increase spine fusion: a double-blind, randomized, placebo controlled study. Spine. 2002;27(13):1383-9.

20. Oro A, Buser Z, Brodke DS. Trends and costs of external electric bone stimulators and grafting materials in anterior lumbar interbody fusion. Asian Spine J. 2018;12(6):973-80.
21. Goodwin CB, Brighton CT, Guyer RD, Johnson JR, Light KI, Yuan HA. A double-blind study of capacitively coupled electrical stimulation as an adjunct to lumbar spinal fusions. Spine. 1999;24(13):1349-56.

22. Phillips M, Drew B, Sprague S, Aleem I. Efficacy of Combined Magnetic Field Treatment on Spinal Fusion: A Review of the Literature. J Long Term Eff Med Implants. 2016;26(3):271-6.

23. Zhang L, Li EN. Risk factors for surgical site infection following lumbar spinal surgery: a metaanalysis. Ther Clin Risk Manag. 2018;14:2161-9.

24. Schoenfeld AJ, Ochoa LM, Bader JO, Belmont PJ. Risk factors for immediate postoperative complications and mortality following spine surgery: a study of 3475 patients from the National Surgical Quality Improvement Program. J Bone Joint Surg. 2011;93(17):1577-82.

25. Park P, Lau D, Brodt ED, Dettori JR. Electrical stimulation to enhance spinal fusion: a systematic review. Evi Based Spine Care J. 2014;5(2):87-94.

Cite this article as: Raiszadeh $\mathrm{R}$, Raiszadeh $\mathrm{K}$, Eaton L, Kim P, Kim C. Effectiveness of combined magnetic field bone growth stimulation on lumbar spinal fusion outcomes: a single center retrospective analysis comparing combined magnetic field to nostimulation. Int J Res Orthop 2020;6:435-41. 